\title{
Empowering Learners with Role-Playing Game for Vocabulary Mastery
}

\author{
Aam Ali Rahman \\ Universitas Pendidikan Indonesia \\ Bandung, Indonesia \\ Anggi Angraeni \\ Universitas Pendidikan Indonesia \\ Bandung, Indonesia
}

\begin{abstract}
The current issue of industrial revolution 4.0 in Indonesia opens many opportunities for innovation in education. This circumstance arouses researchers' interest to create the most innovative strategies and techniques in language learning, especially in teaching vocabulary. It makes the use of computers as media inevitable. This research dealt with the use of computer Role-Playing Game (RPG) as vocabulary learning media. A quasi-experimental study was used to analyse the effect of the media on students' vocabulary mastery. This research aimed to investigate the significant effect of RPG on students' vocabulary mastery and also their responses toward the media. Comparative analysis using $t$-test calculation was employed. It worked with two groups: an experimental and a control group. The statistical result was analysed, and supported by students' responses toward the game as a vocabulary learning tool, including its application in the classroom activities. Based on the statistical result, the experimental and control groups were significantly different. The experimental group tended to have a better rating than the control group. It was supported by the finding that students believed the media could force them to implicitly learn vocabulary. To some extents, the RPG was sufficient to develop students' ability in mastering vocabulary.
\end{abstract}

Keywords: Language Learning; Role-Playing Game; Vocabulary Mastery

\section{Introduction}

The common stereotype of people about vocabulary is a long list of words from textbooks, spelling word lists, or even the multiple lists of terms to study for examination only. This condition drives many researchers to innovate the techniques to teach vocabulary. The most common way applied by teachers is using flashcard, and it becomes an easy technique in mind. As a result, it may 
create a common childhood experience of having to "go look up the words in the dictionary, write the definition, and write a sentence using the terms," but how many of that words' list remains.

More techniques come as alternatives to solve the issue. First is "Look and Remember" technique. This technique asks students to typically stare to the words and their definition, apparently trying to activate their super memory they wish they had. Another technique is related to "word-rehearsing." Students are asked to say the terms over and over again in the exact language and format with the original definition.

While both techniques are considerably effective to enhance students' vocabulary mastery, compared to other considerably stronger techniques, "Look and Remember," and "Word-Rehearsing" seems seductive (Haycraft, 1993), it works only for the short terms, and rarely results in sustained memory. Nevertheless, related studies of vocabulary mastery (Bytheway, 2015; Diaz, 2015; Naeimi \& Foo, 2015; Teng, 2015) offer excellent ways to learn vocabulary. Those studies promote that a meaningful context has to be applied to learn vocabulary, and it stores to learners' long-term memory using various methods of learning. On the other words, vocabulary has to play as a set of meaningful experiences for which students understand the new terms contextually and have an opportunity to put them in different contexts. Hence, the stereotype definition of vocabulary is gradually changing. It is not a series of words to learn but a series of words used in contexts.

Therefore, an issue arises in applying the technique. Habitually, secondary school teachers in Indonesia require their students to memorize the list of vocabulary. It results to students who perform well in memorizing the list consider having higher vocabulary mastery. It is believed that their scores in vocabulary quizzes or unit tests are representing students' vocabulary skills. Yet, the actual test is whether they still remember the tested terms in a few months later. If students cannot maintain and use those new terms, then the whole teaching, learning, testing and exercising are critically a waste of time.

Even though specific and perfect techniques to teach vocabulary to students do not exist, still, vocabulary is a basic communication and most likely plays as a big problem for foreign language learners. In fact, more and more language learners depend on dictionary and utilize it for further usage including lexicographic quality (Lew \& Szarowska, 2017). In consequence, considering how important learning vocabulary for language learners, another technique to learn new vocabulary terms is required.

Generally, every teaching and learning activity engages learning goals and learning strategies for students and teachers (Suherdi, 2009). If learning goals cannot be achieved, the analysis may only be referred to those elements. Either the teachers apply unsuitable teaching technique or students who may lose interest to learn.

In non-English spoken countries, like Indonesia, the chance of failure in mastering vocabulary in higher, since learning vocabulary mostly takes place only in class during English lessons. It results learners have a very limited time to gain and to practice the new terms in the meaningful context. This condition 
is quite impossible to eliminate, yet modifying the teaching techniques and learning media may help them (Suherdi, 2009).

By combining meaningful teaching techniques and learning media, effective learning can possibly dispel and reduce the failure of vocabulary learning. In this case, creating well-made approaches, well-planned method and wellapplied techniques are required, so it can stimulate students to be active learners in their own right (D. Brown, 2001; Cameron, 2010). Unfortunately, no single formula exists to create meaningful and effective vocabulary teaching. The instructional method has been researched to be an effective method to teach vocabulary (McKeown, 2019), and the other promotes a novel method (He \& Godfroid, 2018).

Furthermore, besides learning media and teaching techniques, another factor affecting successful vocabulary learning is students' motivation. Learning motivations along with learning strategies have a positive correlation with grades (Zhang, 2018). It can be assumed that the more attractive and innovative learning media is, the easier the students to learn vocabulary, and the more interesting the media is the higher the motivation of students to learn it.

The use of technology in classroom activity changes students' mind a lot. This circumstance advance education application of the computer and phone that provide rapid growing resources for language learning. Because of that, learning language, especially learning vocabulary, has been developed to take advantage of technology in the classroom. Hence, it promotes Computer-Assisted Language Learning (CALL) (Beatty, 2003; Egbert, 2005). As learning media, innovation in teaching techniques and students' motivation are keys to successful learning activities, a game is one way to work out the problems. The game encourages, entertains, teaches and promotes fluency. It brings natural native languages in a meaningful context.

Besides that, vocabulary mastery has been developed for a traditional classroom type of learning using computers and phones. It offers the unique advantage of learning, analysing and both the development of vocabulary knowledge and usage. In particular, in Indonesia, a litter work has been carried out on vocabulary mastery using a computer game which specifies for learning media in the classroom. Some ethical restrictions to bring phones to the class avoid the usage of media to the classroom activities. However, conducting teaching activities in the computer laboratory offers an innovative and meaningful way of teaching to students.

One appropriate computer game is applied for this study. The game has a visual and verbal explanation of vocabulary. It offers examples that are comprehensive enough for students to understand the term. The most important from all, the game is Role-Playing typed Game (RPG) where the player roles as the main character on the game. This RPG provides actual conversation and meaningful action for the player. Thus, this computer RPG is chosen and utilized as a media in the classroom vocabulary learning activities.

In sum, this study investigates the use of computer Role-Playing Game (RPG) to enhance students' ability in mastering vocabulary. By referring to the previous research and theories, using computer Role-Playing Game in classroom learning 
activities as a media can help students to develop their skill in mastering vocabulary. Afterwards, this study aimed to investigate the effectiveness of playing computer role-playing game to enhance students' ability in mastering vocabulary, and the response of participants toward the computer RPG as vocabulary learning media.

\section{Method}

\section{Research Design}

This paper used quantitative analysis with a quasi-experimental design. The design was chosen to test the hypothesis. In order to get the result, three groups were involved. The first group was a try-out class. This try-out class was used to test the instrument. The class was given 60 vocabulary questions in the form of multiple choices. The Pearson Product Moment Correlation Coefficient Value was used to find the instruments' validity, and Kuder Richardson-20 to analyse the reliability. The second group was a control group, and the last is an experimental group. In addition, a questionnaire and interview were used to triangulate the data.

\section{Participants}

The main prerequisite of population and sample for this study was participants should know how to operate a computer, and to engage with it continually. Furthermore, they should not have ever played the sample computer RPG before. Thus, purposive sampling was chosen. The target population for this study is homogeny population. Therefore, the same grade students in the same school were gathered as participants.

Nevertheless, the number of participants in both the experimental and control group were 20 students, two different tests were given; normal distribution and homogeneity of variance. These tests aimed to identify the t-test suitability.

For further explanation, to test the validity and reliability of the instruments, a try-out group which consists of 25 students were used. The experimental group was given the chosen media and the control group learned vocabulary along with normal classroom activities. Both the experimental and control groups were treated in 10 class sessions.

\section{Learning Media (The Computer RPG)}

One of computer role-playing game was chosen as the vocabulary learning media. The game was selected since it provides audio and visual aids for the learners. This game was also produced and published in the English language. Thus, the participants engage with the contextual English given by its native. The game also provides subtitle for every utterance spoken by every character. In this game, players control the main character and decide what the main character will do. It makes players get a lot of opportunities to read. Reading 
and comprehending the context and text are required to finish the game. The example of the activities in the game can be seen on Picture 1.
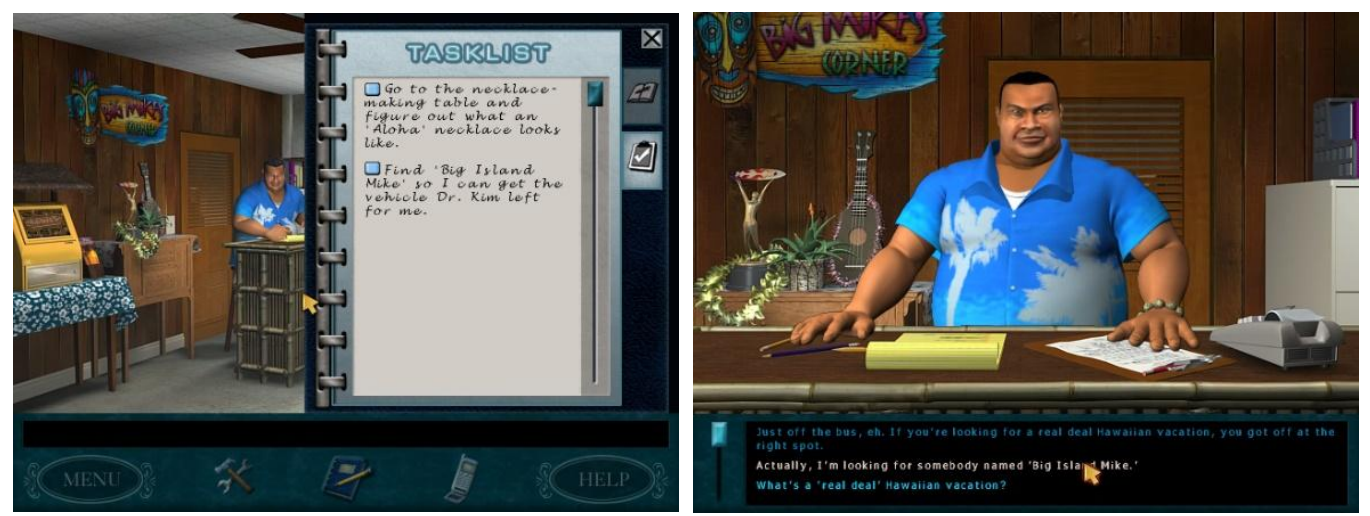

Picture 1: The sample activities provided on the game (HeRInteractive, 2006)

Picture 1 shows how players engage with the selected game. This computer roleplaying game gives some tasks for the players to finish. Players cannot continue the game if the tasks given cannot be fulfilled. All tasks require the players' understanding of the context provided. Players may explore the environment inside of the game to find the clues. Even, players may interact with other characters in the game and ask questions by choosing the options provided. Players may decide by their own to interact with any character in the game, and choose their own preferred question to ask.

However, in this game, the questions have already prepared by the program, the answers have also been programmed to repetitively give the same responses for the same questions chosen by the players. Players cannot write their own question, and cannot naturally interact with the characters in the game. Generally, this computer role-playing game provides native English speakers to dub the characters in the game. This game also gives the players to experience more meaningful vocabulary terms applied in meaningful contexts. The vocabulary terms provided in the game are considered a productive vocabulary that can be used and reproduced in the daily conversation context. For those reasons, this computer RPG was utilized as vocabulary learning media.

\section{The Procedure of the Study}

After three groups of the participants were chosen, a valid and reliable vocabulary test was created. The test items were created by considering the syllabus of targeted groups to create the learning goals, and eleven vocabulary aspects: boundaries between conceptual meanings, polysemy, homophony, homonymy, synonymy, affective meaning, style, register, dialect, translation, chunks of language, the grammar of vocabulary and pronunciation (Lewis, 1993). Further, the targeted vocabulary terms were taken from part of the conversations in the selected game.

The vocabulary test was given to both control and experiment groups as a pretest. This pre-test was used to check both class homogeneity. Afterwards, the 
same vocabulary test item was tested to both control and experiment groups after both groups treated in eight sessions of leaning. The result of the post-test was analysed to check the effectiveness of the computer role-playing game to enhance participants' vocabulary mastery by comparing both control and experiment groups using parametric $t$-test calculation.

\section{Data Analysis}

The concept of eleven vocabulary aspect from Lewis (1993), and high-school English syllabus were used to comprehend the most suitable material for this study, as the participants were high-school students. Those eleven vocabulary aspects are boundaries between conceptual meaning, polysemy, homophony, homonymy, synonymy, affective meaning, style, register, dialect, translation, chunks of language, the grammar of vocabulary and pronunciation. Meanwhile, the target words used as the instrument were taken from several conversations existing in the computer role-playing game given. The chosen words are only highlighted words requiring players to understand the meaning if not, they cannot continue to play to the next scene.

To analyse the result, independent $t$-test was employed to see whether the mean score of two independent groups differs to a statistically significant degree. The result of the pre-test was used to test the normal distribution and homogeneity of participants. The result of normal distribution data can be seen in Figure 1.

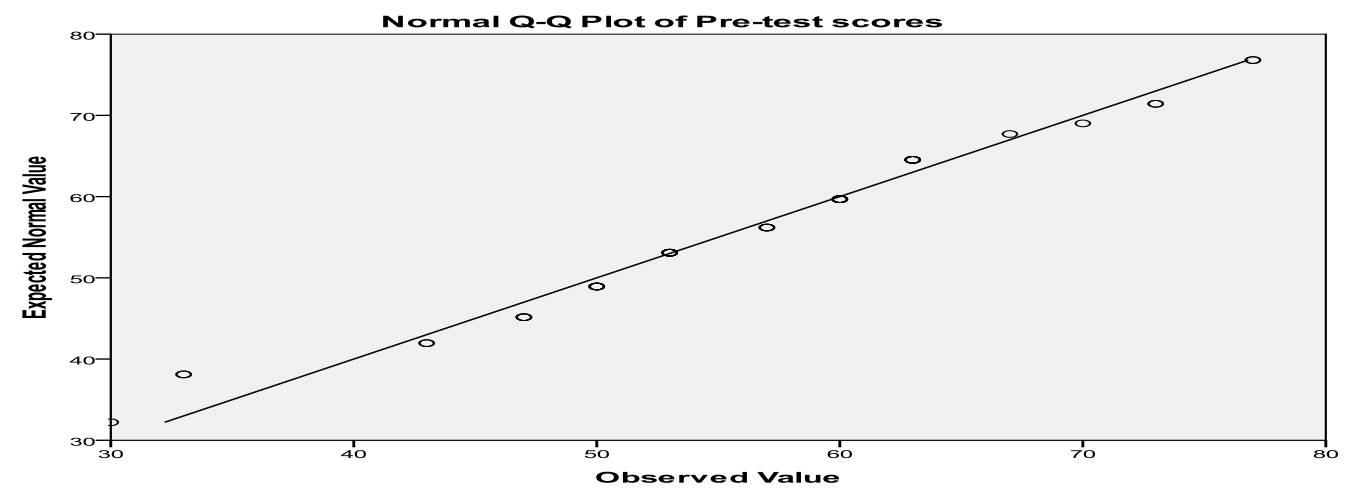

Figure 1: The result of normal distribution test.

The vocabulary test using the developed instrument was applied to both control and experiment groups to check whether both groups were normally distributed in mastering vocabulary or not. Based on Figure 1, the result of pre-test analysis using SPSS 18, both groups had a normal distribution range. The observed values were forming in one straight diagonal line to expected normal value. In other words, both control and experiment groups had normal distribution participants. In addition, Barlet Formulae (Riduwan, 2004) was used to analyse the groups' homogeneity. The result can be seen in Table 1. 
Table 1: The result of the homogeneity test for the pre-test.

\begin{tabular}{|l|c|c|c|}
\hline \multirow{2}{*}{ Group } & \multirow{2}{*}{$n$} & \multicolumn{2}{|c|}{ Test } \\
\cline { 3 - 4 } & & Chi-square & t-test \\
\hline Control & 20 & 0.345575 & 0.688 \\
\hline Experiment & 20 & 0.05 & 0.05 \\
\hline \multicolumn{2}{|l}{ Significance level } & & \\
\hline
\end{tabular}

Two different tests were used to check participant in both experiment and control groups homogeneity. The score results of pre-test from both groups were also used to analyse their homogeneity. Non-parametric calculation using chisquare was used to check participants' homogeneity, and it was supported by $t$ test result. Table 1 shows that both control and experiment groups are homogeneity.

The result of chi-square observed (0.345573) was lower compared to the chisquare table (3.841) with the degree of freedom 1 and level of significance 0.05 . This result was similar when applying the $t$-test calculation. With the level of significance 0.05 and degree of freedom 38 , the result of the calculation was 0.688. The result felt below the $t$-table for those criteria (2.042).

On the other words, since both test result felt below the required, so it can be said that statistically, there was no significant difference in term of mean scores for both groups. It means the experiment group and the control group considered had a similar level of vocabulary mastery before the treatments were conducted to both groups. Further, the parametric calculation can be used to test both experiment and control groups using non-directional $t$-test.

\section{Finding and Discussion}

The non-directional $t$-test was applied to the result of post-test. Since it employed non-directional $t$-test, the hypothesis used was null-hypothesis: there is no significant difference for both experiment and control groups after the treatment. This null-hypothesis was used to overcome the expected research outcome. It gave three option: to accept the result statistically; to negatively reject the result; to positively reject the result. The result can be seen in Figure 2 .

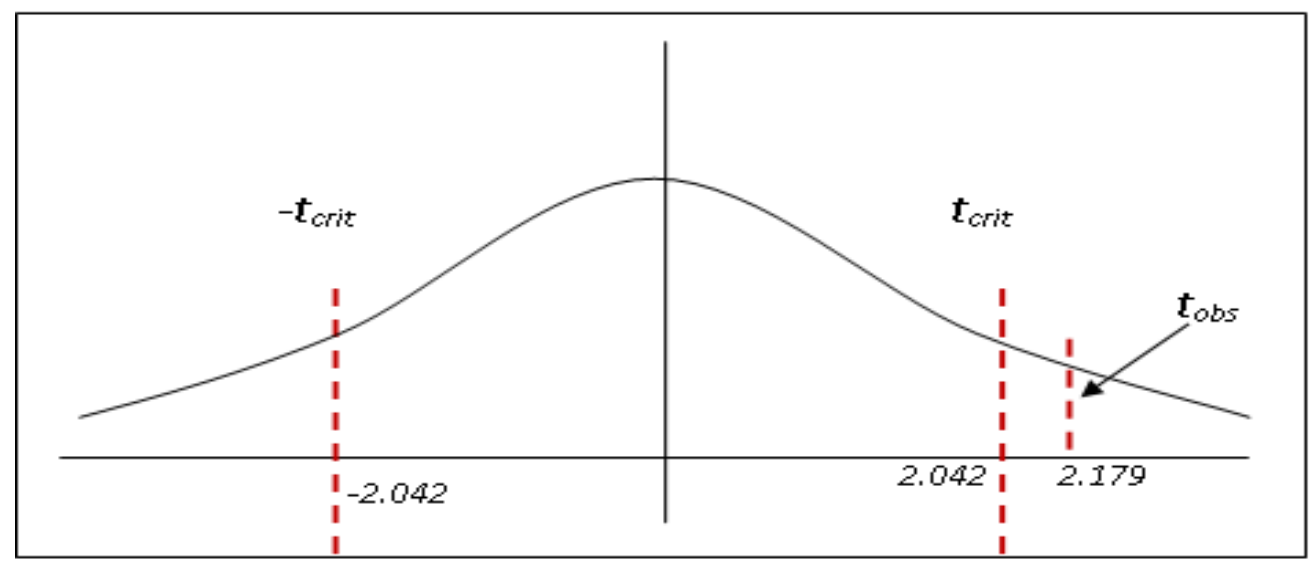

Figure 2: Curve of non-directional test for $d f=38 \approx 30$ and $a=0.05$ 
Based on Figure 2, it can be stated that with the level of significance 0.05 , the $t$ observed is 2.17864 . This result falls positively above the $t$-critical for $d f=38 \approx 30$ (2.042). It means that the null-hypothesis is rejected. The $t$-observed felt positively higher than $t$-critical. It means that the scores difference between the experiment group and the control group is quite noticeable. The experiment group had statistically higher scores compared to the control group after the eight sessions with the different treatment applied. Thus, the computer role-playing game is assumed successful to enhance students' ability to master vocabulary. Further discussion about the process and prejudices are provided in the following discussion.

\section{Improving New Vocabulary Terms Using Computer RPG}

As it is shown in Figure 2, playing selected computer RPG is effective to develop vocabulary mastery. The investigation of these improvements is related to students' tendency to implicitly learn without knowing it. It reduces students' level of boredom. The degree of excitement is necessary for computer-based learning material, particularly for young learners who have less motivation.

However, within the classroom environment, computers can help to motivate through the organization of learning into game-like formats, or even the pure game format.

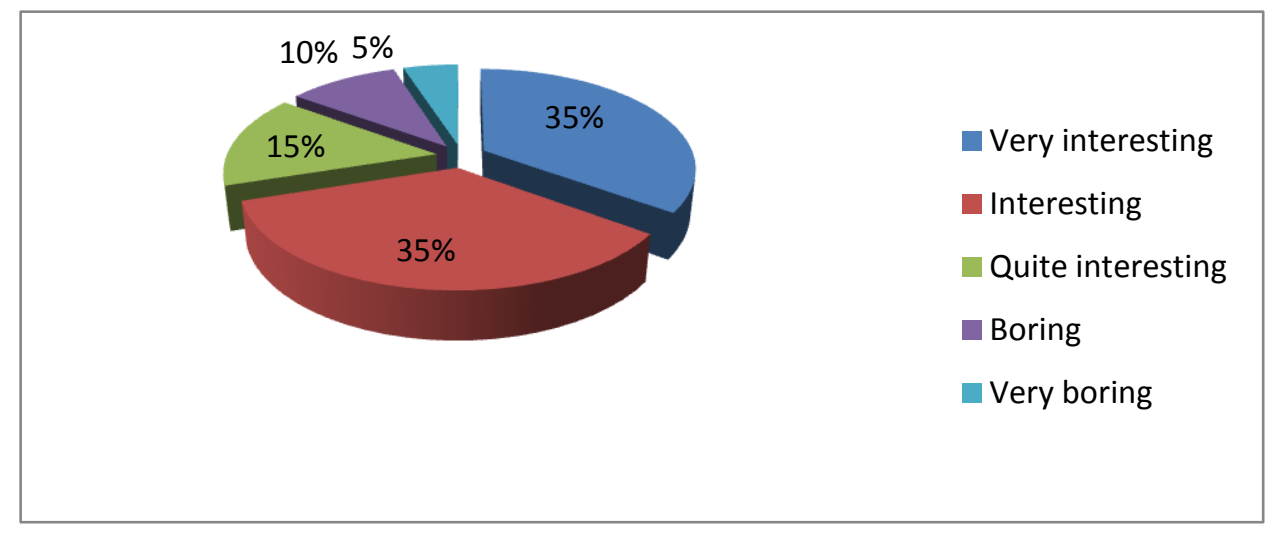

Figure 3: Students' opinion about playing computer RPG

The data in Figure 3 is taken from the questionnaire given to participants in the experiment group. More than half of the group believe that playing computer RPG is interesting, and they love to have the game as part of classroom activity. Participants in the experiment group find it joyful to play compared to the usual teaching and learning activity since there is no pressure to learn. Furthermore, playing the game also offer amusement and different environment in the classroom. 
In contrast, students who found it boring argued that the game actually offered great entertainment, but they believed it should be used in the classroom activity. They assumed playing game may result in laziness, and affects their motivation when the game is no longer played. Some believed that playing the game should not be for learning, but it was only suitable for leisure time.

In learning vocabulary, phycological condition of learners affects the way the terms stored in learners' memory (Nation, 2012). The more students enjoy the activity, the better understanding of new terms can achieve. The integrated theory of computer-assisted language learning or CALL with games may result in supportive learning factors and meaningful context, even it can provide an actual context in the virtual world. Integrating game with computer-assisted language learning provides fun learning, more attention span, more stimulated and motivated, get to use language and involve a lot of repetitions. Those advantages simultaneously result from process variable in the classroom and learning activities that can create a long term effect on players in simple ways.

In non-CALL environment and teaching using multimedia, a teacher tends to be the centre of information, so the learning result is too dependent on the teachers' experiences; formative, training and teachers' properties. However, in the adapted model of integrating game to CALL environment, teachers are no longer the centre of information, yet the collective experiences of material developers become the source of information.

By having English native developers and producers for the media uses in English language learning environment, it provides sources that are more realistic to the context of English. The expression, the pronunciation and the naturalness of the English language can be provided in the classroom by nonnative teachers of English. The role of teachers in this integrated CALL environment is to creatively analyse the suitable type of game to apply.

Computer role-playing games as vocabulary learning media owns information structured on a series of level encouraging readers to operate various levels, at any point, to delve deeper into the explanation. Thus, the media should provide the highest level of revised bloom taxonomy offered (Adesoji, 2018). For an instant, when a program presents thematic vocabulary, the learners might be allowed to follow more explanation to more complex expression uses in vocabulary learning. Such programs might also ask students to recall information and able to apply what they have learnt to the new meaningful context.

Meanwhile, another significant point for students when learning vocabulary is learners' memory. Many types of games can help the teachers to put new terms in learners' memory easy and long-term (Marzano, 2005). In playing the game, learners found some intricacies to do the next steps because of a lack of vocabulary understanding. However, it becomes an effective strategy to activate learners' meta-learning skill. Learners force themselves to find the intended vocabulary terms.

Several tendencies of self-learning within participants when playing the game indicate that every participant actually is able to activate their meta-learning skill if they want. From the questionnaire result, generally, there are three ways 
to solve and to learn new vocabulary terms explicitly. On the other words, the game gives them the motivation to open a dictionary, to ask their friends and to guess the meaning based on the context. It can be seen in Figure 4 .

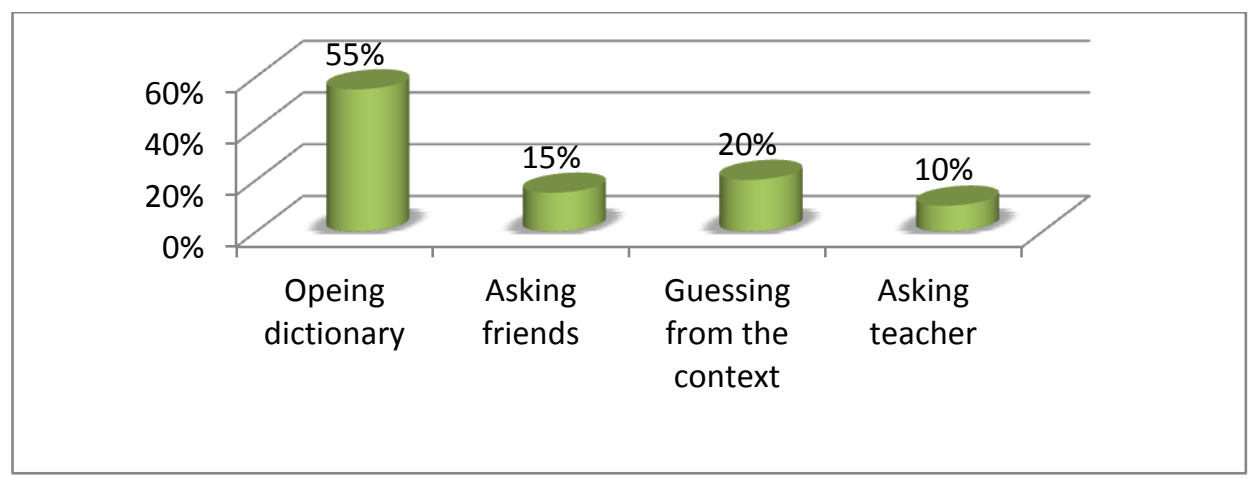

Figure 4: Students' effort to understand new vocabulary terms

In Figure 4, most of the learners prefer opening the dictionary, in total, $90 \%$ of participants chose their own ways to understand the new vocabulary terms. Only $10 \%$ of participants asked the teachers. This circumstance indicates that learners' motivation during the application of playing computer RPG increases as they enjoy the process of vocabulary learning through the media.

Those efforts are the main point of vocabulary self-learning, and by doing selflearning. This self-learning can crate long-term memory (Cameron, 2010). Furthermore, the main issue in teaching vocabulary is that learners only need to know a few words and a small part of the word that can be dealt with at any one time (Nation, 2012). In other words, if learners think that they need to learn the new vocabulary terms, they will learn it, and vice versa. Because of that, teachers should realize that learners will not learn unless they believe they need it.

In this case, a computer role-playing game offers a portrait of life where players can experience themselves as they do conversation and adventures in the game. Players also interact with other artificial characters and doing and acting the natural conversation. Nation (2012) considers this circumstance as a productive vocabulary. Implicitly, participants are experiencing not only new terms but also how to use them; in what context and how to link them with other terms to build meaningful contexts.

\section{The Significance of the computer RPG effects on Students' vocabulary mastery}

As it was stated in Figure 2, the level of significance used for this study is 0.05 . Factors affecting this result are assumed to be fun factors, exploratory learning with large amounts of language data, individualization, various learning styles and resources and real-life skill-building (H. D. Brown \& Lee, 2015).

Meanwhile, the data gathered that $65 \%$ of students can still memorise the new terms they got after finishing the game (8 sessions). Vocabulary learning using diagrams, pictures or other various media can help learner memorising the new terms better (Cameron, 2010). By having those various media, fun factors during 
vocabulary learning help learners to memorise the new terms. In this case, playing the computer role-playing game only has less possibility to effectively enhance learners' ability in mastering vocabulary. Teachers as facilitators have to play their role by giving stipulation to retain the vocabulary mastery. Teachers have to do recalling the new terms and use them in conversation.

Egbert (2005) defines computers in the Computer Assisted Language Learning approach utilize only as media, so the aims of lesson are still language learning, not the technology or giving excitement for the learners. Thus, comprehending the media of learning computer RPG with teachers' role as facilitators to retain learners' memory. This can activate the naturalistic setting of the verbal working memory of learners when learning a second language in the classroom (Verhagen \& Leseman, 2016).

\section{Students' responses toward the computer RPG as vocabulary learning media}

Based on the data collected from the experiment group, $70 \%$ of participants found this interesting and offered great excitement. As learners are native to computers these days, applying this media is not impossible. This stipulation indicates that outside school hours, learners can also play other games and learning more vocabulary terms by themselves. Thus, learners find computerassisted language learning or even phone-assisted language learning is a combination of joy and effective vocabulary learning.

The fact that most popular games are published in English, it offers various great learning aids to language learners. It provides abundant of English native speakers with meaningful context as examples. The computer role-playing game used for this study was developed by native speakers of English. The characters on the game speak native-standardised English as they are dubbed by English natives. In this case, it is like inviting some native speakers of English to the classroom activities.

Furthermore, by the fact that participants found this media interesting, participants can learn better (Cameron, 2010). Interesting learning material can raise learners curiosity to do what they interested in. Self-motivation to learn new terms can be activated automatically. Learners are no longer rely on to the teachers. Finding a new thing without any help from others is parts of acquisition, in which acquiring something is different than learning something. When someones acquire, he/she memorises better than learning (Ellis, 1994; Gass \& Selinker, 2008).

Another advantage of using the computer RPG as a vocabulary learning media is learning time span. This learning time span is very much depended on the learning environment. When learners enjoy the environment, the learners' time span for learning is increasing (H. D. Brown \& Lee, 2015). By using this computer RPG, the learning environment is built not like a common learning activity, yet it is just enjoying the game, not for learning. In addition, the unfamiliar words occurred in the game give learners more opportunities to learn new terms. 
However, the actual and meaningful language offered is not that actual. The game provides the answer for the questions given by the characters on the game. Players are only required to choose the limited possible option. Players also cannot interact with the characters in the game naturally, and the characters only reply repetitively to the chosen answers. The complete vocabulary learning: orthography, syntax, association, grammatical functions and meaning and form (Webb, 2005) cannot be comprehended. The game can only cover association, grammatical function and some part of meaning and form. Because of that, the role of teachers is still required in classroom activities.

Some very unfamiliar words also create burdens for participants. These less familiar words indicate the vocabulary mastery of participants. 85\% of participants in the experiment group reported many terms in the context are unfamiliar for them. Meanwhile, reasonable vocabulary coverage to understand the full text is estimated at $98 \%$ (Schmitt, Jiang, \& Grabe, 2011). In consequence, the application of this computer role-playing game as a media to master vocabulary should be accompanied by the teachers who are ready to utilize the media, so learners get a continuous guide in applying it in the classroom.

The role of the teachers is also required to create the suitable lesson planning. The clear objectives and teaching plans are the successful keys to achieve the vocabulary mastery. Teachers decide and emphasize the objectives they want to achieve. Although this computer role-playing game assumes has a large amount of material from vocabulary to communication skill, still, focusing on the objective is a must to limit the area of joy. Learners are not too overwhelmed with joy, but they can keep focusing on language learning.

In general, this computer role-playing game can only be served as a language learning media, not a full learning source. It still requires teachers to control the learning activity, and it also needs suitable planning and focuses objectives before applying as part of classroom learning activities.

\section{Conclusion}

The most important aim of this study was to see the effectiveness of using the computer role-playing game to enhance learners' vocabulary mastery. The computer RPG was utilized as a learning media in classroom activities. The findings of this study were indicative of the fact that the use of the selected computer role-playing game had a positive significant effect on participants vocabulary mastery. The data gathered and the analysis counted supported the finding of this study. This successful media offers great excitement for learners to learn and helps teachers to achieve the learning objectives.

Learners are encouraged to learn in the classroom, as the computer role-playing game provides a joyful environment and a meaningful experience. It also brings native English speakers to the classroom without actually inviting them. Teachers also find this media helpful because the media can easily be applied and effective, particularly to motivate learners and to keep the vocabulary terms in a longer time span. In the same line, teachers role as a curriculum developer and actual planner along with a facilitator in the classroom. 
Finally, the point should be underscored that this study had some limitations which can be an option for future research. Firstly, the participants in this study were limited to those who had difficulty in understanding the text coverage. A different result might be produced if the study is conducted to more advanced learners. Secondly, language learning using the computer RPG may be suitable not only for vocabulary learning but may also be for other language learning area. Finally, because of the time limit, caution should be made about undertaking the result of participants' performance of this study, or in other words, some other factors might have affected the result of this study.

\section{Acknowledgement}

The authors would like to acknowledge the game developer HeR Interactive for the computer role-playing game (HeRInteractive, 2006). The game was used in the classroom activities for high school students.

\section{References}

Adesoji, F. A. (2018). Bloom Taxonomy of Educational Objectives and the Modification of Cognitive Levels. Advances in Social Sciences Research Journal, 5(5). doi:10.14738/assrj. 55.4233

Beatty, K. (2003). Teaching and Researching Computer-Assisted Language Learning. Edinburgh: Pearson Education Limited.

Brown, D. (2001). Teaching by Principles; An Interactive Approach to Language Pedagogy (2 ${ }^{\text {nd }}$ ed.). San Francisco: San Francisco State University Press.

Brown, H. D., \& Lee, H. (2015). Teaching by Principles: An Interactive Approach to Language Pedagogy (4th ed.). White Plains, New York: Pearson Education ESL.

Bytheway, J. (2015). A taxonomy of vocabulary learning strategies used in massively multiplayer online role-playing games. CALICO Journal, 32(3), 508-527. Retrieved from www.jstor.org/stable/calicojournal.32.3.508.

Cameron, L. (2010). Teaching Languages to Young Learners. Cambridge: Cambridge University Press.

Diaz, I. (2015). Training in Metacognitive Strategies for Students' Vocabulary Improvement by Using Learning Journals. PROFILE Issues in Teachers' Professional Development, 17(1), 87-102. doi:10.15446/profile.v17n1.41632

Egbert, J. (2005). CALL Essentials; Principles and Practice in CALL Classrooms. Virginia: Teachers of English to Speakers of Other Languages Inc.

Ellis, R. (1994). The Study of Second Language Acquisition. Oxford: Oxford University Press.

Gass, \& Selinker. (2008). Second Language Acquisition: An Introductory Course. New York: Routledge Taylor and Francis Group.

Haycraft, J. (1993). An Introduction to English Language Teaching (Revised Impression ed.). England: Longman Group Limited.

He, X., \& Godfroid, A. (2018). Choosing Words to Teach: A Novel Method for Vocabulary Selection and Its Practical Application. TESOL Quarterly, 53(2), 348371. doi:10.1002/tesq.483

HeRInteractive. (2006). Nancy Drew: The Creature of Kapu Cave. London: Simon and Scluchter Inc.

Lew, R., \& Szarowska, A. (2017). Evaluating online bilingual dictionaries: The case of popular free English-Polish dictionaries. ReCALL, 29(2), 138-159. doi:10.1017/s0958344016000252 
Lewis. (1993). The Lexical Approaces. Cambridge: Cambridge Language Teaching Publications.

Marzano, R. J. (2005). Building Background Knowledge for Academic Achievement. Virginia USA: Association for Supervision and Curriculum Development.

McKeown, M. G. (2019). Effective Vocabulary Instruction Fosters Knowing Words, Using Words, and Understanding How Words Work. Lang Speech Hear Serv Sch, 50(4), 466-476. Retrieved from https://www.ncbi.nlm.nih.gov/pubmed/31600467. doi:10.1044/2019_LSHSSVOIA-18-0126

Naeimi, M., \& Foo, T. C. V. (2015). Vocabulary Acquisition through Direct and Indirect Learning Strategies. English Language Teaching, 8(10), 142-151. doi:10.5539/elt.v8n10p142

Nation, I. S. P. (2012). Learning Vocabulary in Another Language (Cambridge Applied Linguistics). Cambridge: Cambridge University Press.

Riduwan. (2004). Metode dan Teknik Menyusun Tesis. Bandung: Alfabeta.

Schmitt, N., Jiang, X., \& Grabe, W. (2011). The Percentage of Words Known in a Text and Reading Comprehension. The Modern Language Journal, 95(1), 26-43. doi:10.1111/j.1540-4781.2011.01146.x

Suherdi, D. (2009). Mikroskop Pedagogik: Alat Analisis Proses Belajar Mengajar. Bandung, Indonesia: CELTICS Press.

Teng, F. (2015). Assessing the Relationship between Vocabulary Learning Strategy Use and Vocabulary Knowledge. PASAA: Journal of Language Teaching and Learning, $49,39-65$.

Verhagen, J., \& Leseman, P. (2016). How do verbal short-term memory and working memory relate to the acquisition of vocabulary and grammar? A comparison between first and second language learners. J Exp Child Psychol, 141, 65-82. Retrieved from https://www.ncbi.nlm.nih.gov/pubmed/26340756. doi:10.1016/j.jecp.2015.06.015

Webb, S. (2005). RECEPTIVE AND PRODUCTIVE VOCABULARY LEARNING: The Effects of Reading and Writing on Word Knowledge. Studies in Second Language Acquisition, 27(01). doi:10.1017/s0272263105050023

Zhang, L. (2018). Analysis and Research on Science Technology Students' English Learning Strategies and Motivation. Adcance in Social Science, Education and Humanities Research, 252, 775-778. doi:doi.org/10.2991/jahp-18.2018.158 